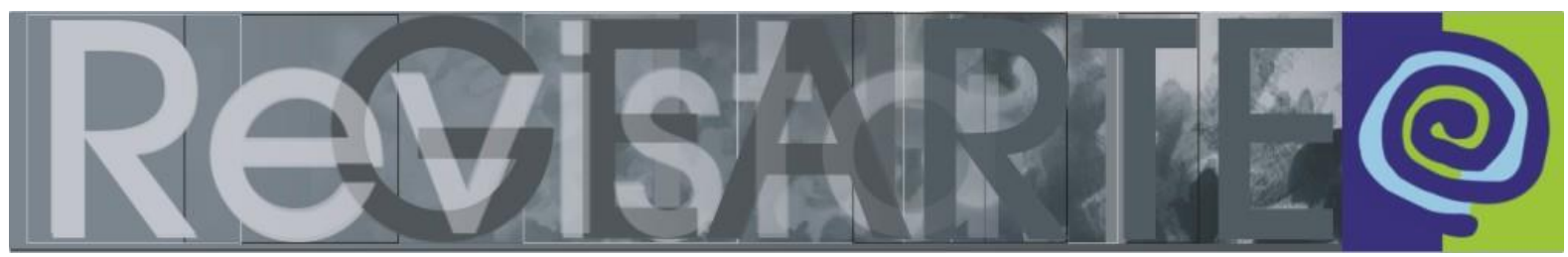

e-ISSN 2357-9854

\title{
Bricolagens entre Cultura Visual e Pedagogias Culturais - possibilidades para o ensino de Artes Visuais
}

\author{
Jéssica Maria Freisleben (Universidade Federal de Santa Maria — UFSM, \\ Santa Maria/RS, Brasil) \\ Ana Lúcia Louro Hettwer (Universidade Federal de Santa Maria — UFSM, \\ Santa Maria/RS, Brasil)
}

\begin{abstract}
RESUMO - Bricolagens entre Cultura Visual e Pedagogias Culturais - possibilidades para o ensino de Artes Visuais - Este texto destaca possibilidades para o ensino de Artes Visuais, a partir de bricolagens com a Cultura Visual e Pedagogias Culturais, campos de estudos que vem crescendo do Brasil, nas últimas décadas. Apresentam-se como possibilidades profícuas pelo protagonismo estudantil e preocupação com as imagens e artefatos culturais, tão presentes na contemporaneidade. Configura-se como um recorte da pesquisa de mestrado. Têm-se como objetivo sinalizar as possibilidades de problematizações de ambos os campos, entendendo-as como potentes aliados ao ensino de Artes Visuais. A partir dos escritos de Hernández (2000, 2007); Cunha (2010, 2012); Martins (2006); Steinberg e Kincheloe (2001, 2004); Tavin e Anderson (2010); se faz uma revisão bibliográfica e destaca-se possibilidades para um ensino de Artes Visuais aliado às demandas da atualidade.
\end{abstract}

\section{PALAVRAS-CHAVE}

Ensino de Artes Visuais. Cultura Visual. Pedagogias Culturais. Bricolagens.

ABSTRACT - Bricolage between Visual Culture and Cultural Pedagogies - possibilities for the teaching of Visual Arts - This text shows possibilities for the teaching of Visual Arts, from DIY with Visual Culture and Cultural Pedagogies, fields of study that has been growing in Brazil in the last decades. They present themselves as possibilities of student protagonism and concern with images and cultural artifacts, so present in contemporary times. It is set as a cut of the master's research. Thesis of signaling as possibilities of problematization of both fields, understood as potential allies to the teaching of Visual Arts. From the writings of Hernández (2000, 2007); Cunha (2010, 2012); Martins (2006); Steinberg and Kincheloe (2001, 2004); Tavin and Anderson (2010); The magazine is available and presents itself for the teaching of Visual Arts to the demands of the present time.

KEYWORDS

Visual Art Education. Visual Culture. Cultural Pedagogies. DIY.

\section{Introdução}

As direções sugeridas pela contemporaneidade permitem diálogos entre perspectivas e abordagens de ensino de origens múltiplas, originárias de diversas partes do mundo. Nessa escrita, apresento a Cultura Visual e as Pedagogias Culturais como possibilidades para o ensino de artes, numa tentativa de bricolar com o que o cenário educacional contemporâneo nos oferece. Tratam-se de estudos iniciados na 
Europa e Estados Unidos, que tem sido férteis em pesquisa e práticas de ensino, em território brasileiro.

O campo da Cultura Visual possibilita extensa gama de discussões, questionamentos e interpretações a respeito das imagens na atualidade e a relação ou não destas com o passado. Sabe-se que, na escola, a disciplina responsável por desenvolver práticas e problematizações em torno das imagens, atualmente, é a disciplina de Artes Visuais, portanto, a Cultura Visual pode ser entendida um sopro de ar fresco vindo para oxigenar as aulas de Artes Visuais.

Diante das transformações sofridas ao longo do tempo, os conceitos de pedagogia e cultura foram se modificando também, permitindo que o conceito de Pedagogias Culturais ganhasse vida. Com essas mudanças, começa a surgir, assim, a ideia de que aprendizagens podem ocorrer em diferentes espaços e não necessariamente no espaço escolar. E essas aprendizagens oriundas de outros espaços, que não a escola, poderiam ser disparadoras e mobilizadoras de aprendizagens dentro da escola.

Trata-se de dois campos de estudos emergentes, advindos de fora do país, mas que ganharam outros contornos em nosso território. Foi durante a pesquisa de mestrado que, esses dois campos começaram a ser entendidos como potentes para o ensino de Artes Visuais. O termo bricolagens no texto, carrega a noção apresentada nas origens do termo em francês bricolage - no sentido de improviso, de "faça você mesmo", na intenção de que se possa criar propostas de trabalho lidando com o acaso, com o contexto, com os campos apresentados, nesse caso a Cultura Visual e as Pedagogias Culturais.

\section{Apontamentos sobre Cultura Visual e educação}

Entende-se que a Cultura Visual constitui-se a partir de outra perspectiva que não considera somente o valor estético - o qual não se perde, mas é investido de outros poderes que se relacionam ao seu contexto social - o papel dessa imagem na vida e cultura das pessoas. Percebe-se que, é mais pertinente refletir sobre como as imagens são práticas culturais que produzem diferentes significados e proporcionam 
distintas interpretações para cada um que venha a se relacionar com elas. Diante do que expõe Raimundo Martins (2006, p. 78), "o objeto de estudo da cultura visual não é especificamente a arte ou a cultura popular, mas a interpretação crítica da arte, da imagem, do visual". Diante disso, possibilita repensar nossas posições no mundo, questionar as relações de poder que são exercidas sobre nós através de imagens e interpretar as imagens que vemos, práticas de grande relevância na contemporaneidade.

Ao mencionarmos Cultura Visual, cabe destacar que, estamos pisando em um terreno ainda bastante movediço, pois referimo-nos a estudos emergentes de um debate, de acordo com o Fernando Hernández (2007), do final dos anos 80, que entremeia discussões de áreas múltiplas como a cultura da mídia, a história da arte, estudos da sociologia da cultura, da área do cinema, da linguística, dos estudos da cultura visual, dentre outros. De acordo com a perspectiva do autor, o campo da cultura visual surgiu para problematizar as relações e os posicionamentos sobre os mais diversos tipos de imagens. Conforme apontado por Juliana Salbego (2017);

\footnotetext{
Estes estudos emergem, assim, como resultado de uma condição histórica em que a produção de bens materiais e simbólicos aumenta progressivamente em função dos desenvolvimentos tecnológicos e das tecnologias de comunicação e nas quais outras disciplinas mais antigas como a estética e história da arte (tradicionalmente 'detentores deste conhecimento') já não podiam dar conta. (SALBEGO, 2017 p. 28)
}

Dentro desse contexto emergente, torna-se interessante também diferenciar imagem e visualidade. De acordo com Salbego (2017), a visualidade difere da imagem no que envolve uma experimentação (das imagens em seus mais diversos tipos) e toda a gama de valores, sentidos e emoções movimentadoras do processo. As imagens, por si só, são inertes; por outro lado, o movimento de relação, estabelecido a partir do sujeito, produz a visualidade. Diante essa distinção, podemos pensar em imagens como disparadoras para esse processo de experimentação salientado pela autora, e esses processos podem estar presentes na escola desde cedo.

A partir dessa virada, entende-se que a relação entre imagem/ artefato e sujeito é o que interessa, e não há nenhum tipo de "poder" na obra em si, como se todas as respostas, sentidos, informações estivessem contidas na obra (objeto) e não na relação 
ou saberes invocados no diálogo por e com ela, ao se produzir sentidos diversos. A partir do presente alargamento de possibilidades, pode-se tomar como apropriação simbólica, tanto um quadro consagrado na História da Arte, quanto um anúncio publicitário, pois o que está em jogo não é o que esse artefato 'carrega consigo', mas a experimentação que aquele sujeito faz dele e como isso muda o sujeito consumidor.

A relação que estabelecemos com as imagens nos faz agora questioná-las, tendo em pauta as relações de poder que exercem. De acordo com Fernando Hernández (2007),

o debate do que denominamos por cultura visual, converge uma série de propostas intelectuais em termos das práticas culturais relacionadas ao olhar e às maneiras culturais de olhar na vida contemporânea, especialmente sobre as práticas que favorecem as representações de nosso tempo e leva-nos a repensar as narrativas do passado. (HERNÁNDEZ, 2007, p. 22)

Portanto, favorecer práticas culturais que desestabilizem noções naturalizadas apresenta-se fundamental na contemporaneidade. Entretanto, o fato não é, na escola, ensinar 'o que ver e como ver', mas estimular o estudante a questionar o que vê, problematizar as relações que tem com o mundo visto e suas formas de compreensão por meio das visualidades. Igualmente, compreender que os artefatos culturais nos ensinam sobre nós mesmos e sobre nossas culturas. Conforme Hernández (2000),

a educação para a compreensão da cultura visual (...) é o estudo e a decodificação desses produtos culturais mediáticos. Conhecimento que talvez seja conveniente aprender na escola, se o que se persegue é que os indivíduos respondam indefesos diante da enxurrada mediática que lhes cai em cima. (HERNANDEZ, 2000, p. 43)

Na escola, a Cultura Visual pode possibilitar a criação de outras interpretações, por meio da problematização das imagens e de artefatos. O estudante pode desenvolver-se criticamente através dessas problematizações, sobretudo, em relação à sedução que as imagens podem despertar. Nas palavras de Martins (2006), a problematização "auxilia a criar e aguçar um sentido de responsabilidade diante das liberdades decorrentes desse poder". Nesse ambiente, podemos exercitar práticas que nos levem a não ser passivos diante das imagens e do que a mídia homogênea tenta nos impor. 
Diante disso, talvez uma saída seria propor, em sala de aula, experimentações artísticas que tomem como ponto de partida imagens oriundas da grande mídia, podendo ser uma alternativa de ação artística com os/as estudantes. Para potencializar a questão, Susana Rangel nos oferece pistas sobre a importância desse alargamento de possibilidades ao se trabalhar com imagens no ensino de artes,

\begin{abstract}
entendo que o ensino de arte hoje deveria ter, como uma de suas principais preocupações, a discussão sobre os efeitos das imagens, a constituição da visualidade e o poder das imagens em produzir verdades. Isso não significa abandonar nas salas de aula o conhecimento sobre a Arte, as mediações objetivando buscar as expressões singulares dos estudantes, as experimentações com diferentes suportes e materiais, a produção de linguagens, entre outras possibilidades do trabalho pedagógico em arte, mas significa acréscimos ao ensino de arte que mais se preocupou com os "objetos" de conhecimento do que como esses conhecimentos produzem os sujeitos da educação. (CUNHA, 2012, p.102)
\end{abstract}

A ideia central apresentada pela autora é a de ampliação e acréscimo ao ensino de arte. Argumenta que as experimentações de cunho mais tradicional, explorando materiais, aproximando-se de obras e artistas consagrados e a busca por produções singulares, continuarão presentes na escola, o que se amplia é a oferta de imagens, que podem vir a ser da cultura midiática, pois fazem parte da vida da maioria dos(as) estudantes, uma vez que as produções televisivas, fílmicas, publicitárias, da web, entre outras produções culturais participam efetivamente da vida das crianças, de seus imaginários, criando modos de ser e relacionar-se com o mundo. Essas imagens cotidianas exercem algum tipo de atração que nos envolve e seduz. Como aponta Giroux (1995, p. 62), "o poder visual destas imagens é tão intenso e convincente que há uma adesão admirativa quase que imediata e, em função disto sequer são questionados seus significados". Assim sendo, como negligenciar essa satisfação estética e o deleite afetivo que a maioria dos(as) estudantes têm com os artefatos culturais populares? Porque não problematizar seus significados e criar, a partir desses mesmos artefatos, outras narrativas oferendo outros sentidos?

\title{
Pedagogias Culturais - um novo caminho de possibilidades
}

A partir das transformações nos conceitos de cultura e pedagogia, condições e possibilidades para a emergência do conceito de pedagogias culturais foram surgindo. 
Com as pedagogias culturais, as noções de espaços onde ocorrem aprendizagem foram ampliadas. Segundo Andrade (2016),

parece-me que hoje entendemos e concordamos que a cultura, em seus diversos espaços de circulação, produz conhecimento, regula e governa, que trabalhamos com o conceito de pedagogias culturais é flexibilização e pluralização do conceito de pedagogia. (ANDRADE, 2016, p. 76)

Começa a surgir, assim, a ideia de que a aprendizagem pode ocorrer em diferentes espaços e não necessariamente no espaço escolar. Os autores Shirley Steinberg e Joe Kincheloe (2004) consideram as grandes corporações, incluindo as midiáticas, como as principais produtoras da cultura infantil contemporânea e estabelecem o estatuto do que vem a ser a infância no mundo de hoje. Apresentamse modelos, não de maneira obrigatória, mas de maneira eficaz, de como ser menina e menino, que muitas vezes são adotados pelas crianças e pouco problematizados dentro das escolas. Em uma rápida passagem pelas salas de aula, poderemos constatar a presença de artefatos culturais advindos, em sua maioria, de produções midiáticas, estampadas nos cadernos, mochilas, lancheiras, roupas, calçados e qualquer suporte passível de ser estampado. Portanto, os itens que os/as estudantes levam para a escola não são apenas o caderno, o livro, o lápis, a borracha e o apontador. Não são apenas os materiais solicitados pela escola através da listinha de materiais. O caderno levado não é apenas um caderno, é também a possibilidade de ter o seu personagem preferido estampado na capa e presente na sala de aula, produzindo sentidos e modelos de ser e se comportar. É a possibilidade de combinar a mochila da Barbie, por exemplo, com o tênis, igualmente rosa, e com o adereço do cabelo, enfim, cria-se a possibilidade de ser um outdoor ambulante das marcas e ícones que escolhemos e que estão de acordo com os modelos apresentados para cada gênero. Encontramos essas referências nas brincadeiras, gestos, expressões, entre outras manifestações, modos de ser e agir, calcados ainda em modelos femininos frágeis e dóceis e modelos masculinos fortes e ágeis. Além da utilidade e beleza dos produtos, deve-se atentar para o que ensinam explícita ou implicitamente.

Mas, de fato o que seriam essas "Pedagogias Culturais"? Conforme Tavin e Anderson (2010) e Steinberg e Kincheloe (2004), as Pedagogias Culturais estão relacionadas à redução de fronteiras entre conhecimentos cotidianos e da cultura de 
massa com os conhecimentos tradicionalmente escolares, entendendo que a cultura é uma importante fonte de aprendizagem, aproximada de nós em forma de desenhos animados, programas de televisão, filmes, entre outros e que nos fornecem prazer e informação, e por vezes influenciam o consumo. Remete-nos a múltiplos locais sociais, que não necessariamente as instituições educacionais de fato. Locais onde aprendemos sobre o mundo e nossas relações sociais, as vezes sem nos darmos conta que estamos aprendendo.

O que está fora da escola também faz parte dela, conforme Silva (2009) "as outras instâncias culturais também são pedagógicas, também têm uma "pedagogia", também ensinam alguma coisa" (SILVA, 2009, p.139). Parece-me que os/as estudantes talvez, antes mesmo de seus/suas professores, já tenham se dado conta da noção de aprendizagem fora da escola, com algo de sua escolha e em ambientes/espaços/situações que fogem aos espaços educativos tradicionais. O que me faz pensar que a etimologia da palavra "educação" se aproxima do latim educare, educere, que significa literalmente, "conduzir para fora", preparar os sujeitos para o mundo, para a vida. E esse "fora" tem espaço dentro da escola?

Se depender dos/as estudantes, esse "fora" entra na escola, o que pode nos levar a incentivar e vivenciar o protagonismo estudantil. Diante da "invasão" dos artefatos na sala de aula, é perceptível que as escolhas feitas fora da escola acabam adentrando esse espaço. Porém, acredito que esses artefatos não invadem a escola, pois em meu entendimento eles são convidados a fazer parte das aulas, o que às vezes gera competição entre os conteúdos eleitos como escolares e os conhecimentos do cotidiano, que emergem das pedagogias culturais. Atualmente, temos diante de nós uma multiplicidade de imagens e artefatos culturais, tornando-se difícil ignorá-los como constituidores de imaginários e subjetividades. Como nos lembra Cunha (2008), os artefatos culturais e imagens produzem modos de agir e não são inocentes objetos/utensílios que apenas cumprem suas funções utilitárias, o que corrobora a pensarmos em práticas pedagógicas que atentem a essas questões. Diante disso, pensar as pedagogias exercidas pelas imagens e artefatos culturais torna-se tarefa potente para aquelas/es que trabalham na educação, sobretudo aos que lidam diretamente com campos artísticos. 
Talvez, seja interessante entendermos que aprendizagem não está limitada aos muros da escola e "a forma envolvente pela qual a pedagogia cultural está presente nas vidas de crianças e jovens não pode ser simplesmente ignorada por qualquer teoria contemporânea do currículo" (SILVA, 2009, p.140). Pelo contrário, pode fazer parte da vida escolar e das práticas pedagógicas e artísticas planejadas pelos docentes. Diante disso, as práticas escolares podem ser consideradas e problematizadas a partir de modificações que a sociedade em geral vem passando e as relações das crianças com diferentes pedagogias culturais. O autor Douglas Kellner (1995) também sinaliza essa necessidade.

\begin{abstract}
outras máquinas de imagem geram uma quantidade imensa de artefatos impressos, sonoros, ambientais e de natureza estética diversa, dentro dos quais vagamos, tentando encontrar nosso caminho dentro dessa floresta de símbolos. E assim precisamos aprender a ler imagens, essas formas culturais fascinantes e sedutivas cujo impacto massivo sobre nossas vidas apenas começamos a compreender. A educação certamente deveria prestar atenção a essa nova cultura, tentando desenvolver uma pedagogia crítica que estivesse preocupada com a leitura de imagens. Um tal esforço seria parte de um nova pedagogia radical que tentasse ir à raiz de nossa experiência, nosso comportamento e conhecimento e que objetivasse a liberação da dominação e a criação de novos eus, plurais, fortalecidos e mais potentes - ideias característicos tanto da teoria moderna quanto da pós-moderna." (KELLNER, 1995, p.109)
\end{abstract}

Como destaca Susana Rangel (2010), parece que a escola ainda escolhe conteúdos canônicos, em detrimento às aprendizagens sedutoras, múltiplas e relacionais que acontecem fora da escola. Tomar como disparador a sedução exercida pelas pedagogias culturais não quer dizer reduzir o papel do professor, apenas é uma forma de valorizar os conhecimentos dos/as estudantes sobre o mundo fora da escola, sobre as suas escolhas e o que entendem sobre elas.

De acordo com o que nos apresenta Hernández (2007), significa optar por um tema que tenha a ver com suas inquietudes, que
represente desafios para eles, que os convide a fazer relações e a desfrutar
do prazer de aprender. Não se trata, contudo, de colocar em pauta o que eles
"gostam" ou o que Ihes "interessa", simplesmente, mas, propor algo que os
incomode e desafie, colocando em circulação diferentes saberes e
provocando o envolvimento dos sujeitos (HERNANDEZ, 2007, p.82-83).

Não se trata de escolher o que os/as estudantes gostam simplesmente por querer agradá-las e facilitar as relações entre professor(a) e estudante, mas sim por 
entender a potência e(du)vocativa que imagens e artefatos culturais apresentam ao ensinar formas de ser e atuar, ao evocar apreensões que participam dos imaginários coletivos e individuais, a partir de suas qualidades afetivas (VALLE, 2016). De acordo com Nunes (2014), “isso não significa 'pedagogizar' as imagens ou artefatos culturais, transformando-os em conteúdos, mas trazer para as salas de aula as discussões, as problemáticas e os conflitos mediados por esses elementos culturais.", pois a escola pode ficar alienada a essas questões.

\section{Bricolagens entre Cultura Visual e Pedagogias Culturais}

Diante dessas verificações, e muitas outras, busco ampliar as discussões e reflexões sobre as imagens e os efeitos delas sobre nós, entendendo as produções da arte, da cultura visual e das pedagogias culturais como possibilidades para o ensino de Artes Visuais. Indo ao encontro do que aponta Tourinho e Martins (2011),

o propósito da educação da cultura visual não é substituir conceitos, abordagens curriculares ou práticas de ensino da arte, mas introduzir e incorporar no fazer artístico a discussão do lugar/espaços das imagens qualquer imagem ou artefato artístico - e seu potencial educativo na experiência humana. (TOURINHO e MARTINS, 2011, p.57)

Diante dos apontamentos apresentados, talvez seja relevante aos processos pedagógicos da escola problematizar o repertório visual escolhido pelos/as estudantes, incentivando-os a questionar, atentar ao que parece ser imposto, questionar sobre as imagens que seleciona, bem como aquelas que são deixadas de lado. Atividades como essa, tornam-se importante porque analisar artefatos culturais familiares aos estudantes salienta a capacidade de colocar em prática o que é aprendido por eles na escola. Além disso, é necessário instigá-los a pensar (por meio da experiência estética/ visual/ afetiva) como são suas perspectivas frente ao mundo e às relações que estabelecem com seus pares, pois a escola constitui-se um dos espaços onde podem exercitar sua autonomia e/ou negociação com a diversidade de opiniões e posicionamentos.

Ante essa perspectiva, questionar as imagens que se fazem presente diariamente na vida das crianças torna-se tarefa fundamental da escola. Ouve-se tanto em estudante e cidadão crítico, mas como nos tornamos críticos, se práticas 
sociais não forem potencializadas? Acredito que, com algumas mudanças, podemos exercer experimentações na escola que podem nos aproximar de um posicionamento inquiridor, ao menos não passivo diante à mídia.

Entretanto, para que as escolhas estudantis façam parte das propostas pedagógicas, a postura dos/das professores pode se assemelhar a de um bricoleur, que coleta amostras, fragmentos e está atento ao que lhe rodeia e apresenta, assim, estratégias de conectar "conteúdos" da escola e fora dela e recriar narrativas diversas potencializadas pela problematização das imagens da cultura visual. Com esse posicionamento flexível, surgem aberturas para conhecer e problematizar junto às/aos estudantes as influências que escolhem e que podem ser vistas em suas brincadeiras, representações visuais, falas, gestos e modos de ser.

Trata-se, sobretudo, de revisitar imagens e posições com outros modos de discursos, que possibilitem diferentes interpretações e ações. Implica abrir espaço para outras formas de ver e se relacionar com aquilo que se vê e se tem, seja mediante atitudes críticas, reflexivas ou que produzam novas formas de investigação e produção de conhecimentos e significados.

\section{Referências}

ANDRADE, Paula Deporte. Pedagogias Culturais: uma cartografia das (re)invenções do conceito. Porto Alegre: UFRGS, 2016. (Tese de Doutorado) Programa de Pós-Graduação em Educação, Faculdade de Educação da Universidade Federal do Rio Grande do Sul.

CUNHA, Susana Rangel Vieira da. Cultura Visual e Infância. In: REUNIÃO DA ANPED, 31, 2008, Caxambu: 31를 Reunião Anual da ANPED - Caxambu, 2008.p. 102-132.

CUNHA, Susana Rangel Vieira da. Questionamentos de uma professora de arte sobre o ensino de arte na contemporaneidade. In: MARTINS, Raimundo. TOURINHO, Irene (Orgs.) Cultura das imagens: desafios para a arte e para a educação. Santa Maria: Editora da UFSM, 2012, p. 99-124.

DALLA VALLE, Lutiere. (2016) Provocações, (des)continuidades, desfechos: potência edu(vo)cativa das imagens fílmicas na formação docente. Revista da Fundarte, Montenegro, n. 32, p.52-94, 2016.

DENZIN, Norman; LINCOLN, Yvonna. A disciplina e a prática da pesquisa qualitativa. In: DENZIN, Norman; LINCOLN, Yvonna. O planejamento da pesquisa qualitativa: teorias e abordagens. Porto Alegre: Artmed, 2006.

GIROUX, Henry. A disneyzação da cultura infantil. In: Silva, Tomaz T.; MOREIRA, Antônio F. (Orgs). Território contestados: o currículo e os novos mapas políticos e culturais. Petrópolis: Vozes, 1995.

HERNÁNDEZ, Fernando. Cultura Visual, mudança educativa e projeto de trabalho. Trad. Jussara Haubert Rodrigues. Porto Alegre: Artes Médicas Sul, 2000.

HERNÁNDEZ, Fernando. Catadores da Cultura Visual: uma proposta para uma nova narrativa educacional. Trad. de Ana Duarte. Porto Alegre: Editora Mediação, 2007.

FREISLEBEN, Jéssica Maria; HETTWER, Ana Lúcia Louro. Bricolagens entre Cultura 
HERNÁNDEZ, Fernando. La cultura visual como estrategia que posibilita aprender a partir de estabelecer relaciones. Instrumento: R. Est. Pesq. Educ. Juiz de Fora, v. 14, n. 2, jul./dez. 2012.

KELLNER, Douglas. Lendo imagens criticamente: em direção a uma pedagogia pós-moderna. In: SILVA, Tomaz Tadeu (Org.). Alienígenas na sala de aula: uma introdução aos Estudos Culturais em Educação. Petrópolis: Vozes, 1995. p.104-131.

MARTINS, Raimundo. Por que e como falamos da cultura visual? Goiás, VISUALIDADES- FAVIUFG, 2006. p. 63-79.

MARTINS, Raimundo; TOURINHO, Irene. Circunstâncias e ingerências da cultura visual. In: MARTINS, Raimundo; TOURINHO, Irene. Educação da Cultura Visual: conceitos e contextos. Santa Maria: Editora da UFSM, 2011. p. 51-68.

NUNES, Aline B.; MARTINS, Raimundo. (2014) Um convite para "educar"/pensar infâncias líquidas. In: MARTINS, Raimundo; MARTINS, Alice Fátima. (Orgs). Cultura Visual e Ensino de Arte: concepções e práticas em diálogo. Pelotas: Editora UFPel, 2014.

SALBEGO, Juliana. Atravessamentos e visualidades em ambientes educativos: aproximações com o PIBID Artes Visuais/UFSM. Tese (Doutorado em Educação), Universidade Federal de Santa Maria, 2017.

SILVA, Tomaz Tadeu da. Documentos de Identidade: uma introdução às teorias do currículo. Belo Horizonte: Autêntica, 2009.

STEINBERG, Shirley; KINCHELOE, Joe. Cultura Infantil: a construção corporativa da infância. Rio de Janeiro: Civilização Brasileira, 2004.

TAVIN, Kevin; ANDERSON, David. A cultura visual nas aulas de arte no ensino fundamental: uma desconstrução da Disney. In: MARTINS, Raimundo; TOURINHO, Irene (Orgs.). Cultura Visual e Infância: quando as imagens invadem a escola... Santa Maria: Editora da UFSM, 2010, p. 57-69.

\section{Jéssica Maria Freisleben}

Mestre em Educação pelo Programa de Pós-graduação em Educação (PPGE) na Linha de Pesquisa LP4 - Educação e Artes (2016-2018). Licenciada em Artes Visuais-Licenciatura Plena em Desenho e Plástica/UFSM(2012-2016). Atuou como bolsista PIBID- Programa Institucional Bolsas de Iniciação à Docência em Artes Visuais. Foi integrante do Grupo de Pesquisa Artes Visuais e suas I/Mediações e do Ateliê de Pintura 1336 (2012-2016). Integrante do projeto de Extensão: e " Arte Contemporânea e Educação da Cultura Visual: Pedagogias na Alfabetização Infantil". Membro do Coletivo de artistas "Capella". Integrante do Lavi/m - Laboratório Artes Visuais e I/mediações (2017-).

E-mail: jessicafreisleben@hotmail.com

Currículo: http://lattes.cnpq.br/9325987901226540

\section{Ana Lúcia Louro Hettwer}

Possui graduação em Bacharelado em Música pela Universidade Federal do Rio Grande do Sul (1991), mestrado em Música pela Universidade Federal do Rio Grande do Sul (1995) e doutorado em Música pela Universidade Federal do Rio Grande do Sul (2004). Atualmente é Professor Associado da Universidade Federal de Santa Maria. Tem experiência na área de Artes, com ênfase em Educação Musical, atuando principalmente nos seguintes temas: narrativas de si, educação musical, formação de professores, identidades profissionais e cursos superiores de música. É membro das associações ISME, ABEM, ANPPOM, ANPED, BIOGraph.

E-mail: analoock@hotmail.com

Currículo: http://lattes.cnpq.br/8744911424416533

Recebido em 30 de agosto de 2018 Aceito em 24 de novembro de 2018 